\title{
PREDIÇÃO DE GANHOS GENÉTICOS POR ÍNDICES DE SELEÇÃO NA POPULAÇÃO DE MILHO-PIPOCA UNB-2U SOB SELEÇÃO RECORRENTE $\left(^{1}\right)$
}

\author{
FABRÍCIO SANTANA SANTOS $\left({ }^{2}\right)$; ANTONIO TEIXEIRA DO AMARAL JÚNIOR $\left({ }^{*}\right)$; \\ SILVÉRIO DE PAIVA FREITAS JÚNIOR $\left({ }^{4}\right)$; RAMON MACEDO RANGEL $\left({ }^{4}\right)$; \\ MESSIAS GONZAGA PEREIRA $\left({ }^{3}\right)$
}

\begin{abstract}
RESUMO
Com o intento de selecionar progênies superiores para a efetiva concentração de alelos favoráveis em uma população de terceiro ciclo de seleção recorrente intrapopulacional em famílias de meios-irmãos de milho-pipoca, avaliaram-se 192 progênies em delineamento em blocos casualizados com duas repetições em dois ambientes distintos: Colégio Estadual Agrícola Antônio Sarlo, em Campos dos Goytacazes, e Estação Experimental da PESAGRO-RIO, em Itaocara, Rio de Janeiro, em 2004/05. Definiu-se a intensidade de seleção de $15,6 \%$, correspondendo ao número de trinta famílias de meios-irmãos para continuidade do programa. Foram empregados os índices de seleção de Smith e Hazel, Pesek e Baker, Williams, e Mulamba e Mock. O índice de Mulamba e Mock proporcionou as magnitudes mais elevadas de ganhos preditos para a maioria das características, incluindo-se capacidade de expansão e produção, com valores respectivos de 7,16\% e 10,00\%, na utilização de pesos arbitrários atribuídos por tentativas.
\end{abstract}

Palavras-chave: seleção combinada, seleção recorrente, ganho genético.

\section{ABSTRACT \\ GENETIC GAIN PREDICTION BY SELECTION INDEX IN A UNB-2U POPCORN POPULATION UNDER RECURRENT SELECTION}

\begin{abstract}
Aiming to select superior progenies for concentration of favorable alleles in a popcorn population on the third cycle of intrapopulation half-sib recurrent selection, one hundred and ninety-two progenies were evaluated in a completed randomized design with two replications, in two distinct environments: Colégio Estadual Agrícola Antônio Sarlo, located in Campos dos Goytacazes, and Experimental Station of PESAGRO-RIO, located in Itaocara, Rio de Janeiro State, in 2004/05. The selection intensity was $15.6 \%$ that keep in touch thirty half-sib families for the continuity of the breeding program. The utilized selection indexes were the SMITH and HAZEL, PESEK and BAKER, WILLIAMS, and MULAMBA and MOCK. The MULAMBA and MOCK index propitiated more elevated magnitudes of the predicted gains for most of the traits, including popping expansion and grain yield, with values of $7.16 \%$ and $10.00 \%$, respectively, utilizing arbitrary weight attributed by tentative.
\end{abstract}

Key words: combined selection, recurrent selection, genetic gain.

$\left({ }^{1}\right)$ Recebido para publicação em 27 de dezembro de 2005 e aceito em 30 de março de 2007.

$\left({ }^{2}\right)$ Doutor em Produção Vegetal pela Universidade Estadual do Norte Fluminense Darcy Ribeiro (UENF).

$\left({ }^{3}\right)$ Laboratório de Melhoramento Genético Vegetal, Universidade Estadual do Norte Fluminense Darcy Ribeiro, Av. Alberto Lamego, 2000, Parque Califórnia 28013602 Campos dos Goytacazes (RJ). E-mail: amaraljr@uenf.br. $\left({ }^{*}\right)$ Autor correspondente.

$\left({ }^{4}\right)$ Doutorando em Genética e Melhoramento de Plantas pela Universidade Estadual do Norte Fluminense Darcy Ribeiro. 


\section{INTRODUÇÃO}

Apesar de a pipoca ser altamente apreciada no país e a produção de grãos, uma atividade altamente rentável - comparado ao milho comum, o valor comercial do milho-pipoca é três vezes superior - há poucos programas de melhoramento implementados no Brasil para o lançamento de variedades e híbridos (SAWAZAKI, 1995; PACHECO et al., 1998; SAWAZAKI, 2001; SCAPIM et al., 2002).

Em milho-pipoca, a correlação negativa entre as duas principais características de valor econômico - capacidade de expansão e produtividade de grãos - dificulta a seleção de genótipos de interesse para o melhoramento (Lima et al., 1973; Zinsly e MACHADO, 1987; Dofing et al., 1991; Daros et al., 2004a) e torna necessário o emprego de procedimentos genéticoestatísticos que permitam minimizar ou, mesmo, tornar inócuos os efeitos deletérios da resposta correlacionada. Para tanto, os índices de seleção são procedimentos indispensáveis, pois permitem obter ganhos simultâneos mesmo para características com efeitos adversos, que podem ter origem na ligação gênica ou na pleiotropia.

Apesar da enfatizada potencialidade dos índices de seleção no melhoramento de plantas (CRUZ e RegAzZI, 2001), em milho-pipoca, apenas mais recentemente alguns trabalhos têm empregado a metodologia, como, por exemplo, MATA (2000), Vilarinho (2001), Granate et al. (2002) e Santos et al. (2003).

Os índices de seleção permitem gerar um agregado genotípico sobre o qual se exerce a seleção, funcionando como caráter adicional, resultante da combinação de determinadas características escolhidas pelo melhorista, nas quais se deseja exercer a seleção simultânea, permitindo separar genótipos superiores, independentemente da existência ou não de correlações entre características (Sмітн, 1936; Hazel, 1943; Williams, 1962; Castoldi, 1997; Cruz e RegazZI, 2001; Vilarinho et al., 2003).

Sмiтh (1936) propôs o uso de índice de seleção nos programas de melhoramento de plantas como critério de seleção. Hazel (1943) adaptou esse procedimento ao melhoramento animal. De acordo com esses autores, para o estabelecimento do índice de seleção é necessário determinar o valor econômico relativo de cada característica, bem como obter as estimativas das variâncias genotípicas e fenotípicas e das covariâncias fenotípicas e genotípicas entre cada par de características. Este índice de seleção, por ter sido um dos primeiros a ser utilizado, ficou propalado como Índice Clássico.
Comparando os ganhos preditos obtidos com seleção simultânea de características, utilizando-se vários índices de seleção e vários critérios seletivos, GRANATE et al. (2002) concluíram que os ganhos preditos com o índice de seleção de SMith (1936) e Hazel (1943) foram superiores àqueles com outros índices.

O objetivo deste trabalho foi predizer os ganhos genéticos para características de interesse ao programa de melhoramento de milho-pipoca da Universidade Estadual do Norte Fluminense Darcy Ribeiro. Utilizaram-se quatro métodos de índices de seleção com diferentes critérios de pesos econômicos, para identificar o índice e o critério mais adequado à fidedigna composição de 30 famílias de meios-irmãos superiores da população a ser submetida a novo ciclo de seleção recorrente, de modo que promova o efetivo aumento da concentração de alelos favoráveis na população.

\section{MATERIAL E MÉTODOS}

A população de trabalho consistiu de 192 famílias de meios-irmãos, obtidas do ciclo C2 de UNB$2 \mathrm{U}$. Os ensaios de campo foram implantados em Campos dos Goytacazes, em dezembro de 2004, e em Itaocara, em janeiro de 2005, respectivamente, nas regiões Norte e Noroeste Fluminense.

Utilizou-se o delineamento de blocos ao acaso com duas repetições em seis "sets", cada qual constituído de 32 famílias e oito testemunhas. Cada família foi cultivada em linhas de 5,0 m, distanciadas entre si por 1,0 $\mathrm{m}$, empregando-se o espaçamento de $0,20 \mathrm{~m}$ entre plantas. Os tratos culturais foram empregados conforme o recomendado por FANCELLI e Dourado Neto (2000).

Avaliaram-se as seguintes características: altura de planta (AP) e da espiga (AE), obtidas pela média de seis plantas competitivas na parcela, sendo AP medida do solo até o nó de inserção da folha bandeira e AE, do solo até a inserção da primeira espiga superior; estande final (EF), expresso pelo número de plantas contidas na fileira; número de plantas quebradas abaixo da espiga (PQ); número de plantas acamadas (PA) com inclinação $=45^{\circ}$ em relação a vertical; número de espigas mal empalhadas (EME), que não foram cobertas totalmente pela palha; número de dias para florescimento (DF), período compreendido entre a emergência e a liberação dos estilos de pelo menos $50 \%$ das plantas da fileira; número de espigas doentes (ED); número de espigas atacadas por pragas (EP); produção de grãos (PG), transformada em $\mathrm{kg} \mathrm{ha}^{-1}$; massa de cem grãos (P100G); e capacidade de expansão (CE), obtida pela razão entre o volume expandido e a massa da amostra de 30 gramas de grãos. 
As características AP, AE, EF, DF, EME, PQ e PA foram mensuradas no campo, sendo as três primeiras aos 90 dias após o plantio e as demais, por ocasião da colheita, com exceção do número de dias para florescimento.

O teor de umidade dos grãos foi obtido pelo método-padrão de estufa com circulação de $\operatorname{ar}\left(105^{\circ} \mathrm{C}\right.$ $\pm 3{ }^{\circ} \mathrm{C}$, durante 24 horas), com três repetições, de acordo com as Regras para Análise de Sementes (BRASIL, 1992). Os resultados foram expressos em \% de umidade, em base úmida. As amostras foram ordenadas na disposição do sorteio de campo e armazenadas em câmara seca e fria, juntamente com uma amostra-piloto de $1.000 \mathrm{~g}$, para monitoramento da umidade dos grãos. Quando a amostra-piloto atingiu a umidade de $12 \%$, as caixas com as amostras foram retiradas da câmara e colocadas no balcão de trabalho em condições de ambiente. O monitoramento da umidade da amostra-piloto, durante a avaliação de CE, revelou variação de $11,0 \%$ a $12,0 \%$; considerada normal por Alexander e Creech (1977), Hoseney et al. (1983) e PACHECO et al. (1998).

As características P100G e CE foram mensuradas no laboratório, utilizando-se balança de precisão, marca GEHAKA, modelo BG 1000 para a primeira; a avaliação da CE foi realizada em um pipocador desenvolvido pela EMBRAPA/ Instrumentação Agropecuária, com controle de temperatura. Adotou-se o seguinte procedimento: de cada família e testemunha, foram obtidas duas amostras com $30 \mathrm{~g}$ de grãos. Cada amostra foi avaliada no pipocador regulado a $270{ }^{\circ} \mathrm{C}$, por 2,5 minutos. $\mathrm{O}$ volume expandido foi quantificado em proveta graduada de $1.000 \mathrm{~mL}$. A razão entre o volume expandido e a massa inicial proporcionou a magnitude de $\mathrm{CE}$, cujo valor proveio da média de duas amostras de cada parcela.

A análise da variância foi realizada considerando-se o modelo estatístico: $\mathrm{Y}_{\mathrm{ijkl}}=\mathrm{m}+\mathrm{E}_{\mathrm{i}}+$ $S_{j}+E S_{i j}+R / E S_{i j k}+F / S_{j l}+E F / S_{i j l}+x_{i j k l,}$, em que méa constante; $E_{\mathrm{i}}$ é o efeito fixo do i-ésimo ambiente; $S_{\mathrm{j}}$ é o efeito do j-ésimo "set"; ES $\mathrm{ij}_{\mathrm{ij}}$ é o efeito da interação entre

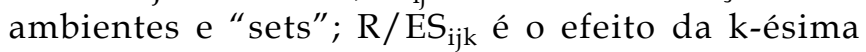
repetição dentro da interação entre o i-ésimo ambiente e o j-ésimo "set"; $F / S_{j l}$ é o efeito do i-ésimo genótipo dentro do j-ésimo "set"; $E F / S_{\mathrm{ijl}}$ é o efeito da interação de ambientes e genótipos dentro do j-ésimo "set", e $x_{\mathrm{ijk}}$ é o erro experimental (Hallauer e Miranda FilHo, 1988).

Cada "set" foi analisado separadamente e os resultados dos seis "sets" foram agrupados para cada ambiente. Finalmente, os resultados de todos os "sets" foram combinados para as duas repetições. Todas as fontes de variação, com exceção de ambiente, foram consideradas aleatórias.
Os índices de seleção empregados para predizer os ganhos foram o Clássico, de SMITH (1936) e Hazel (1943), o proposto por Pesek e BaKer (1969), o de Williams (1962), e o sugerido por Mulamba e Моск (1978).

O índice de Smith (1936) e Hazel (1943) fundamentou-se na solução do sistema matricial: $b=$ $\mathrm{P}^{-1} \mathrm{Ga}$, em que b é o vetor de dimensão $12 \times 1$ dos coeficientes de ponderação do índice, a serem estimados; $\mathrm{P}^{-1}$ é a inversa da matriz de dimensão 12 x 12 de variâncias e covariâncias fenotípicas entre as características; $\mathrm{G}$ é a matriz de dimensão $12 \times 12$ de variâncias e covariâncias genéticas entre as características; e a é um vetor $12 \times 1$ de pesos econômicos. O método de PeseK e BAKER (1969) baseiase nos ganhos desejados para evitar a inexatidão de atribuição de valores aos pesos econômicos e definese por: $b=G^{-1} \ddot{A} g d$, em que Ägd é o vetor de ganhos desejados; $\mathrm{G}^{-1}$ é a inversa da matriz de variâncias e covariâncias genéticas.

O procedimento analítico de Williams (1962) dispensa o uso de matrizes de variâncias e covariâncias, com o intento de evitar estimações imprecisas desses componentes, sendo expresso por: $\mathrm{I}=\mathrm{a}_{1} \mathrm{x}_{1}+\mathrm{a}_{2} \mathrm{x}_{2}+\ldots+\mathrm{a}_{\mathrm{n}} \mathrm{x}_{\mathrm{n}}=\mathrm{a}^{\prime} \mathrm{X}$, em que I é o índice de seleção; $a_{i}$ é o peso econômico atribuído à característica $i$, sendo $i=1, \ldots, n$; a' é o vetor dos pesos econômicos; $x_{i}$ é a média da característica $i$, sendo $i=$ $1, \ldots, \mathrm{n}$; e $X$ é o vetor das médias das $\mathrm{n}=12$, características que constituem o índice. O índice de Mulamba e Моск (1978) hierarquiza os genótipos, inicialmente, para cada característica, por meio da atribuição de valores absolutos mais elevados àqueles de melhor desempenho. Por fim, os valores atribuídos a cada característica são somados, obtendo-se a soma dos "ranks", que assinala a classificação dos genótipos (Cruz e Regazzi, 2001).

Os pesos econômicos adotados foram: a) coeficiente de variação genético $\left(\mathrm{CV}_{\mathrm{g}}\right)$; b) desviopadrão genético $\left(\mathrm{DP}_{\mathrm{g}}\right)$; c) herdabilidade $\left(\mathrm{h}^{2}\right)$; e d) valores atribuídos por tentativas (PT) de magnitudes de $100,100,10,40,40,1,1,1,40,50,40$ e 1 , respectivamente, para as características $C E, P G$, P100G, ED, EP, AP, AE, EF, PQ, PA, EME e DF, que se referem aos valores ótimos para obtenção de ganhos para a totalidade das características. Foram obtidos, aleatoriamente, após atribuição de diversas grandezas. $\mathrm{Na}$ obtenção desses pesos, utilizaram-se 50 simulações, que incluiu a adoção de valores contrastantes para CE e PG, porém, sem desprezar ganhos para as demais características de interesse, como ED, EP, AP, AE, EF, PQ e PA. O Programa GENES (CRUZ, 2001) foi utilizado para realização das análises estatísticas. 


\section{RESULTADOS E DISCUSSÃO}

Os ganhos percentuais preditos para o índice de seleção de SMITH (1936) e Hazel (1943) permitiram a obtenção de ganhos positivos para as principais características - CE e PG -, quando os pesos econômicos atribuídos foram o coeficiente de variação genético $\left(\mathrm{CV}_{\mathrm{g}}\right)$, o desvio-padrão genético $\left(\mathrm{DP}_{\mathrm{g}}\right)$, a herdabilidade $\left(\mathrm{h}^{2}\right)$ e os pesos arbitrários $(\mathrm{PT})$. O ganho percentual conjunto predito para $\mathrm{CV}_{\mathrm{g}}$, $\mathrm{DP}_{\mathrm{g}}$ e pesos arbitrários foi de $20,21 \%$ e, para $h^{2}$, de $20,58 \%$. Quando o peso econômico utilizado foi a razão $\mathrm{CV}_{\mathrm{g}}$ / $\mathrm{CV}_{\mathrm{e}}$ não houve estimativas positivas de ganhos em ambas as características (Tabela 1).

Para as demais características, considerandose como critérios os pesos $\mathrm{CV}_{\mathrm{g}}, \mathrm{DP}_{\mathrm{g}}$ e pesos arbitrários, os ganhos preditos revelaram resultados alvissareiros, sobretudo para EP e PQ, por expressarem sinais negativos, indicando a perspectiva de seleção de genótipos menos propensos ao quebramento e aos danos causados por pragas. Todavia, para as características ED e PA, os valores positivos dos ganhos seletivos revelam que serão selecionados genótipos não promissores quanto à suscetibilidade a doenças e ao acamamento.

Embora $\mathrm{h}^{2}$ tenha expressado ganho conjunto superior em CE e PG; para a característica EP, revelou ganho predito positivo, o que torna esse critério de peso econômico de menor eficiência em relação a $\mathrm{CV}_{\mathrm{g}}$ $\mathrm{DP}_{\mathrm{g}}$ e pesos arbitrários, na seleção de genótipos adequados pelo índice de SMITH (1936) e HAZEL (1943).

Em específico ao peso econômico $\mathrm{CV}_{\mathrm{g}}$, $\mathrm{CRUZ}$ (1990) verificou sê-lo de maior eficiência em relação aos critérios de pesos $\mathrm{DP}_{\mathrm{g}}$ e relação $\mathrm{CV}_{\mathrm{g}} / \mathrm{CV}_{\mathrm{e}}$, para o índice de seleção de SMITH (1936) e HAZEL (1943), por proporcionar ganhos simultâneos mais adequados para a seleção de progênies de milho comum em programa de seleção recorrente.

Ao contrário, MARTins (1999), trabalhando com seleção em Eucalyptus grandis, ao utilizar o coeficiente de variação genético como peso econômico do Índice Clássico, não obteve resultados desejáveis, optando por usar como pesos econômicos valores firmados em estatísticas dos próprios dados.

No primeiro ciclo de seleção recorrente da população de milho-pipoca UNB-2U, utilizando seleção direta para a seleção de progênies superiores em famílias de irmãos completos, DAROs et al. (2002) estimaram ganhos de $10,39 \%$ e $4,69 \%$ para capacidade de expansão e produção de grãos, cujas magnitudes foram inferiores às preditas, no segundo ciclo de seleção recorrente, com famílias endogâmicas (17,80\% e 26,95\% respectivamente) (DAROS et al., 2004b), utilizando-se o índice de seleção de Smith (1936) e HAZEL (1943).
O índice de PESEK e BAKER (1969) proporcionou ganhos positivos simultâneos em CE e PG apenas quando se utilizou o critério $\mathrm{DP}_{\mathrm{g}}$ como peso econômico (Tabela 1). O valor percentual do ganho predito para essas características em conjunto, da magnitude de $22,15 \%$, superou as estimativas dos ganhos conjuntos em CE e PG, expressos pelos demais índices de seleção utilizados.

Porém, $\mathrm{DP}_{\mathrm{g}}$, usado como ponderador econômico para o índice de PESEK e BAKER (1969), não revelou resultados favoráveis de ganhos seletivos para ED, EP e PA. Para essas características, as estimativas percentuais positivas dos ganhos por seleção favorecerão a suscetibilidade a pragas e doenças, bem como o acamamento de plantas. Para a característica AP, embora a estimativa de ganho tenha sido modesta $1,67 \%$ - tornou-se desinteressante em comparação aos resultados expressos pelos índices de WiLLIAMs (1962) e Mulamba e Mock (1978). Esses autores registraram ganhos preditos inferiores para AP, portanto, de maior interesse à seleção de genótipos para o Norte e Noroeste Fluminense, regiões onde a ocorrência de fortes ventos desfavorece a prevalência de plantas mais altas.

Em programa de seleção recorrente, CRUZ et al. (1993), avaliando progênies de irmãos completos de milho comum para composição do lote de recombinação, constataram que, ao contrário da seleção truncada e da resposta correlacionada, os índices de Williams (1962), Smith (1936) e Hazel (1943) proporcionaram ganhos simultâneos para as características teor de óleo e rendimento de espigas, com prevalência de ganhos superiores para o índice de Williams (1962). Por sua vez, Granate et al. (2002), avaliando a população de milho-pipoca CMS-43, obtiveram sucesso na utilização do índice de SMITH (1936) e HAZEL (1943) na predição de progresso desejado nas características altura de planta, produção e capacidade de expansão, quando usaram pesos econômicos obtidos aleatoriamente por tentativas.

O índice de Williams (1962) apenas proporcionou resultado desinteressante para ganhos genéticos simultâneos em CE e PG quando o peso econômico utilizado foi a relação $\mathrm{CV}_{\mathrm{g}} / \mathrm{CV}_{\mathrm{e}}$ (Tabela 2). Em contraposição, GRANATE et al. (2002), ao analisarem a viabilidade do uso do índice de seleção de Williams (1962) em milho-pipoca, utilizando o $\mathrm{CV}_{\mathrm{g}}$ como peso econômico, concluíram que esse coeficiente não permitiu a obtenção de estimativas de ganhos preditos simultâneos nas características PG e CE. De qualquer forma, no presente trabalho, os demais critérios de pesos econômicos empregados para o índice de Williams (1962), embora tenham exibido ganho percentual conjunto de $21,30 \%$ para CE e $P G$, não foram preditivos de ganhos desejáveis para as características ED, EP, AP e AE (Tabela 2). 


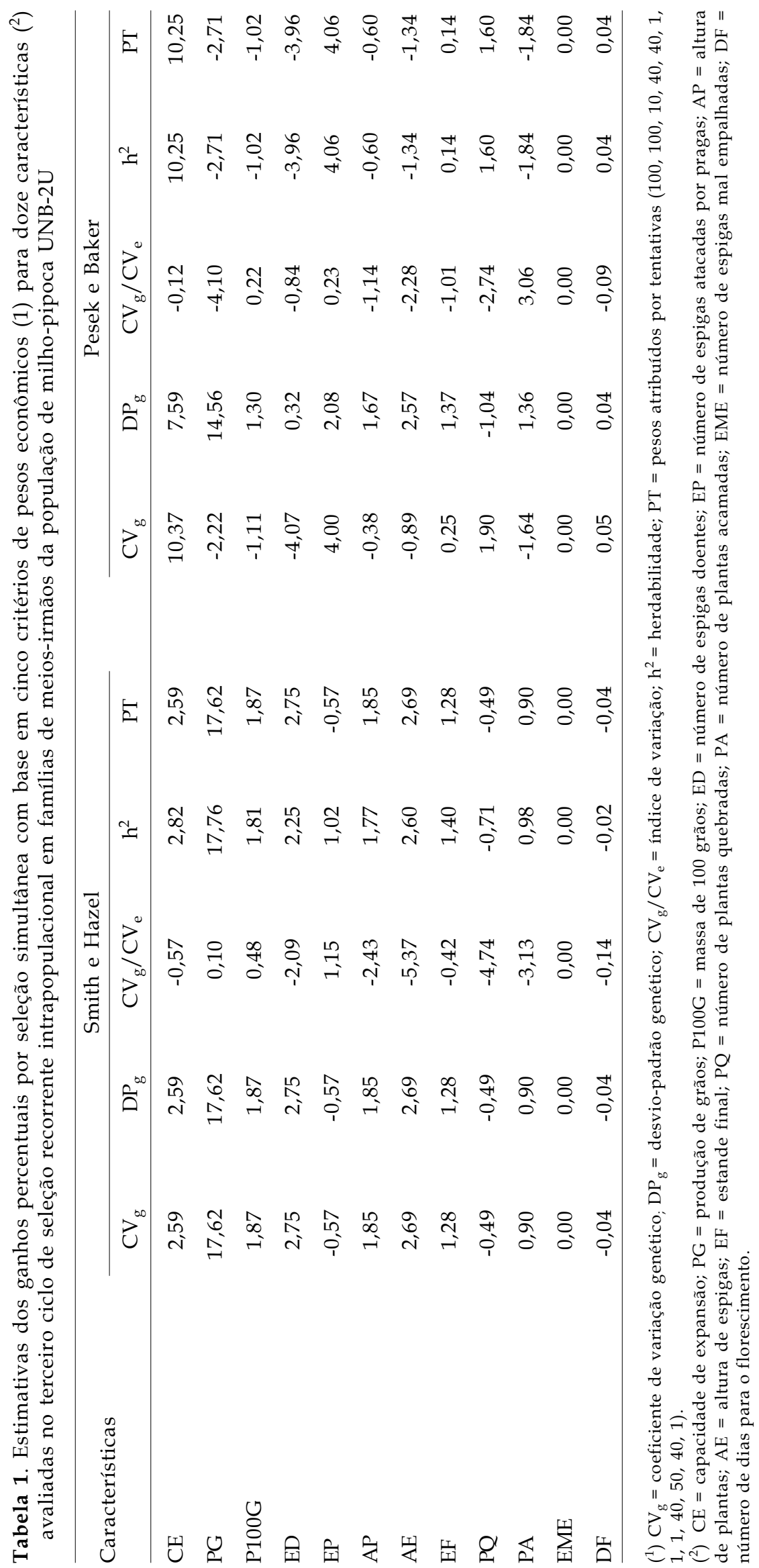




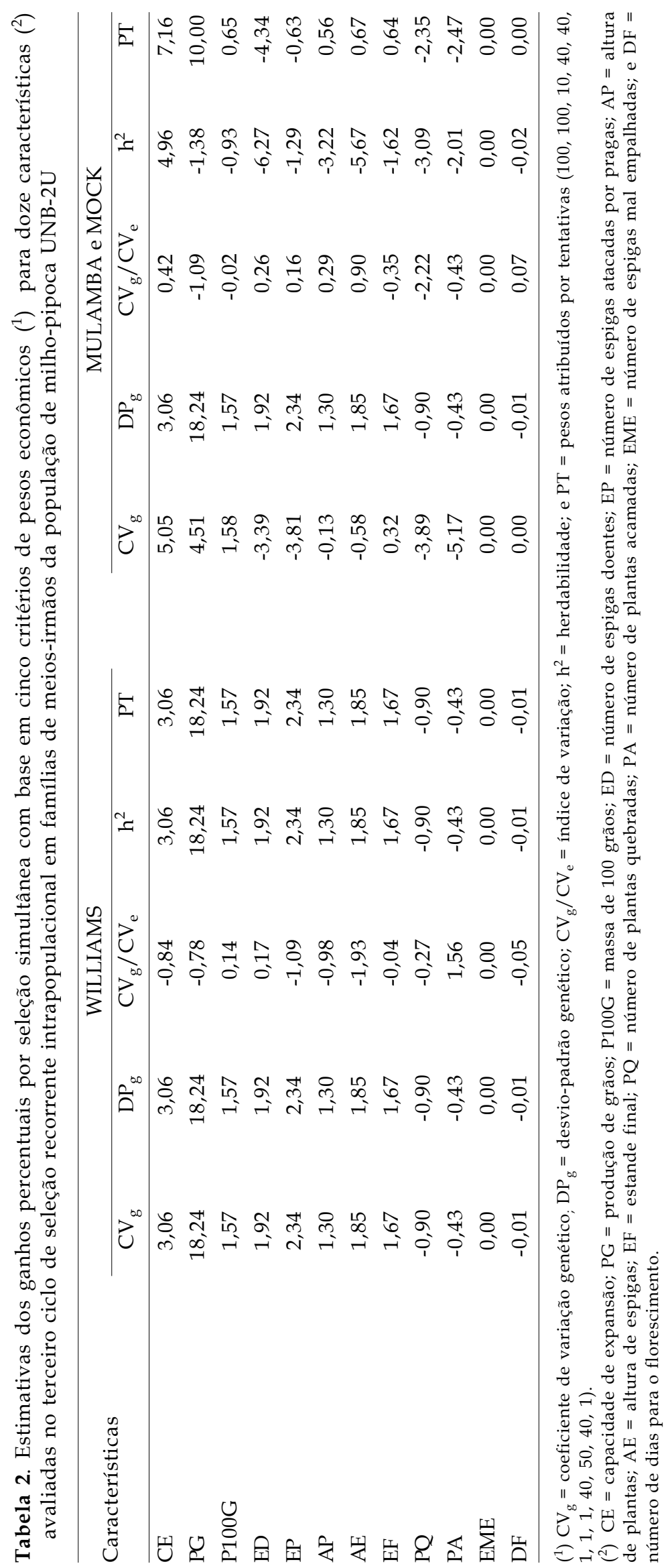


CROSBIE et al. (1980), comparando a eficiência de vários índices de seleção e dos ganhos preditos para cada um deles, no melhoramento da resistência ao frio, em duas populações de milho, observaram que os melhores ganhos em todas as características avaliadas foram possíveis com os índices de seleção de Mulamba e Mock (1978), Subandi et al. (1973), Elston (1963) e de Williams (1962). Consideraram, ainda, que esses índices tiveram a vantagem de não serem afetados pela desigualdade das variâncias das características, bem como de não necessitarem da estimação de parâmetros genéticos.

Por sua vez, VILARINHO et al. (2003), avaliando a eficiência da seleção truncada, dos índices de SMITH (1936); Hazel (1943); Williams (1962); Pesek e Baker (1969); Mulamba e Mock (1978) e Elston (1963), na identificação de progênies $S_{1}$ e $S_{2}$ superiores de milhopipoca, concluíram que na estratégia de seleção recomendada para 30 e 60 famílias o índice de Mulamba e Mock (1978) foi o que proporcionou resultados mais desejáveis para ganhos satisfatórios em produção e capacidade de expansão.

No presente trabalho, a análise das estimativas de ganhos preditos pelo procedimento de Mulamba e Моск (1978) revelou que esse foi o único índice que não proporcionou ganhos idênticos nas características com os critérios de pesos econômicos utilizados (Tabela 2). Esse fato demonstra que quaisquer modificações impostas na classificação dos genótipos afetam diretamente sua hierarquização e, por conseguinte, das estimativas percentuais dos ganhos de seleção para as características.

Dentre as opções de pesos econômicos utilizados para a obtenção de ganhos seletivos pelo índice de Mulamba e Моск (1978), constatou-se que os pesos arbitrários foram os que proporcionaram ganhos mais adequados para as características avaliadas. Em conjunto, CE e PG expressaram ganho percentual de $17,16 \%$. A despeito desse quantum de predição de ganho para as principais características não ter sido o mais elevado, em relativização com os demais índices, houve expressão de ganhos negativos para ED, EP, PQ e PA. Além disso, registraram-se ganhos sobremaneira moderados para $\mathrm{AP}$ e $\mathrm{AE}$; e o percentual seletivo predito para EF não foi negativo.

O índice de Mulamba e Mock (1978), com base em pesos arbitrários, foi o que propiciou os melhores resultados para a seleção das famílias de meiosirmãos, não apenas por proporcionar ganhos satisfatórios para CE e PG, mas também por revelar ganhos negativos para características indesejáveis ao melhoramento do milho-pipoca para o Norte e Noroeste Fluminense.

\section{CONCLUSÕES}

1. O uso de índices de seleção permitiu a predição de ganhos simultâneos nas duas principais características (CE e PG).

2. A seleção das famílias superiores, realizada com base no índice de Mulamba e Mock (1978), produziu ganhos preditos de $7,16 \%$, para capacidade de expansão e 10,00\% para produção, além de ganhos negativos para espigas doentes e atacadas por pragas e plantas acamadas e quebradas, sendo, portanto, o procedimento mais adequado na seleção de progênies superiores para constituírem o terceiro ciclo de seleção recorrente.

\section{AGRADECIMENTO}

À FAPERJ pelo suporte financeiro para a implantação dos experimentos de campo e às análises laboratoriais.

\section{REFERÊNCIAS}

ALEXANDER, D.E.; CREECH, R.G. Breeding special industrial and nutritional types. In SPRAGUE, G.F.; FUCCILO, D.A. (Eds.). Corn and corn improvement. Madison: American Society of Agronomy, 1977. p.363-386.

BRASIL. Ministério da Agricultura e Reforma Agrária. Comissão Técnica de Normas e Padrões. Normas de identidade, qualidade, embalagem e apresentação do milho. Brasília, 1992.

CASTOLDI, F.L. Comparação de métodos multivariados aplicados na seleção em milho. 1997. 118f. Tese (Doutorado em Genética e Melhoramento) - Universidade Federal de Viçosa, Viçosa.

CROSBIE, T.M.; MOCK, J.J.; SMITH, O.S. Comparison of gains predicted by several methods for cold tolerance traits of two maize populations. Crop Science, Madison, v.20, p.649-655, 1980.

CRUZ, C.D. Aplicação de algumas técnicas multivariadas no melhoramento de plantas. 1990. 188f. Tese (Doutorado em Agronomia) - Escola Superior de Agricultura "Luiz de Queiroz", Piracicaba.

CRUZ, C.D. Programa Genes: Versão Windows; aplicativo computacional em genética e estatística. 2. ed. Viçosa: UFV, 2001. 648p.

CRUZ, C.D.; REGAZZI, A.J. Modelos biométricos aplicados ao melhoramento genético. 2. ed. Viçosa: UFV, 2001. 390p.

CRUZ, C.D.; VENCOVSKY, R.; SILVA, S.O.; TOSELLO, G.A. Comparison of gains from selection among corn progenies, based on different criteria. Brazilian Journal of Genetics and Molecular Biology, Ribeirão Preto, v.16, p.79-89, 1993. 
DAROS, M.; AMARAL JÚNIOR, A.T.; PEREIRA, M.G. Genetic gain for grain yield and popping expansion in full-sib recurrent selection. Crop Breeding and Applied Biotechnology, Viçosa, v.2, p.339-344, 2002.

DAROS, M.; AMARAL JÚNIOR, A.T.; PEREIRA, M.G.;SANTOS, F.S.; SCAPIM, C.A.; FREITAS JÚNIOR, S.P.; DAHER, R.F.; ÁVILA, M.R. Correlações entre caracteres agronômicos em dois ciclos de seleção recorrente em milho-pipoca. Ciência Rural, Santa Maria, v.34, p.1389-1394, 2004a.

DAROS, M.; AMARAL JÚNIOR, A.T.; PEREIRA, M.G.;SANTOS, F.S.; GABRIEL, A.P.C.; SCAPIM, C.A.; FREITAS JÚNIOR, S.P; SILVÉRIO, L. Recurrent selection in inbred popcorn families. Scientia Agricola, Piracicaba, v.61, p.609-614, 2004b.

DOFING, S.M.; D'CROZ-MASON, N.; THOMAS-COMPTON, M.A. Inheritance of expansion volume and yield in two popcorn $\mathrm{x}$ dent corn crosses. Crop Science, Madison, v.31, p.715-718, 1991.

ELSTON, R.C. A weight-free index for the purpose of ranking or selection with respect to several traits at a time. Biometrics, North Carolina, v.19, p.85-97, 1963.

FANCELLI, A.L.; DOURADO NETO, D. Produção de milho. Guaíba: Agropecuária, 2000.360p.

GRANATE, M.J.; CRUZ, C.D.; PACHECO, C.A.P. Predição de ganho genético com diferentes índices de seleção no milhopipoca CMS-43. Pesquisa Agropecuária Brasileira, Brasília, v.37, p.101-108, 2002.

HALLAUER, A.R.; MIRANDA FILHO, J.B. Quantitative genetics in maize breeding. Ames: Iowa State University Press, 1988. 468p.

HAZEL, L.N. The genetic basis for constructing selection indexes. Genetics, Austin, v.28, p.476-490, 1943.

HOSENEY, R.C.; ZELEZNAK, K.; ABDELRAHMAN, A. Mechanism of popcorn popping. Journal of Cereal Chemical, New York, v.1, p.43-52, 1983.

LIMA, M.; ZINSLY, J.R.; MÔRO, J.R. Seleção massal estratificada no milho-pipoca (Zea mays L.) visando o aumento da produtividade, caracteres agronômicos e capacidade de expansão. Relatório Científico da ESALQ, Piracicaba, v.7, p.83$88,1973$.

MARTINS, I.S. Comparação entre métodos uni e multivariados aplicados na seleção em Eucalyptus grandis. 1999. 94f. Tese (Doutorado em Genética e Melhoramento) - Universidade Federal de Viçosa, Viçosa.

MATTA, F.P. Seleção entre e dentro de famílias de meiosirmãos na população de milho-pipoca beija-flor (Zea mays L.). 2000. 83f. Dissertação (Mestrado em Genética e Melhoramento) - Universidade Federal de Viçosa, Viçosa.

MULAMBA, N.N.; MOCK, J.J. Improvement of yield potential of the Eto Blanco maize (Zea mays L.) population by breeding for plant traits. Egypt Journal of Genetics and Cytology, Alexandria, v.7, p.40-51, 1978.
PACHECO, C.A.P.;GAMA E.P.; GUIMARÃES, P.E.O.;SANTOS, M.X.; FERREIRA, A.S. Estimativas de parâmetros genéticos nas populações CMS-42 e CMS-43 de milho-pipoca. Pesquisa Agropecuária Brasileira, Brasília, v.33, p.1995-2001, 1998.

PESEK, J.; BAKER, R.J. Desired improvement in relation to selection indices. Canadian Journal of Plant Sciences, Ottawa, v.1, p.215-274, 1969.

SANTOS, F.S.; DAROS, M.; AMARAL JÚNIOR, A.T.; PEREIRA, M.G.; TARDIN, F.D.; RIVA, E.M. Uso do índice de seleção de Smith \& Hazel na população de milho de pipoca UNB-2U para obtenção do segundo ciclo de seleção recorrente. In: CONGRESSO BRASILEIRO DE MELHORAMENTO DE PLANTAS, 02, 2003, Porto Seguro. Resumos... Porto Seguro: Brazilian Society of Plant Breeding, 2003, p.5.

SAWAZAKI, E. Melhoramento do milho-pipoca. Campinas: Instituto Agronômico, 1995. 21p. (Documentos IAC, 53)

SAWAZAKI, E. A cultura do milho-pipoca no Brasil. O Agronômico, Campinas, v.53, n.2, p.11-13, 2001.

SCAPIM, C.A.; PACHECO, C.A.P.; TONET, A.; BRACCINI, A.L.; PINTO, R.J.B. Análise dialélica e heterose de populações de milho-pipoca. Bragantia, Campinas, v.61, n.3, p.219-230, 2002.

SMITH, H.F. A discriminant function for plant selection. Annals of Eugenics, London, v.7, p.240-250, 1936.

SUBANDI, W.; COMPTON, A; EMEIG, L.T. Comparison of the efficiencies of selection indices for three traits in two variety crosses of corn. Crop Science, Madison, v.13, p.184-186, 1973.

VILARINHO, A.A. Seleção de progênies endogâmicas $S_{1}$ e $S_{2}$ em programas de melhoramento intrapopulacional e de produção de híbridos de milho-pipoca (Zea mays L.). 2001. 79f. Dissertação (Mestrado em Genética e Melhoramento) Universidade Federal de Viçosa, Viçosa.

VILARINHO, A.A.; VIANA, J.M.S.; SANTOS, J.F.; CÂMARA, T.M.M. Eficiência da seleção de progênies $S_{1}$ e $S_{2}$ de milhopipoca, visando à produção de linhagens. Bragantia, Campinas, v.62, p.9-17, 2003.

WILLIAMS, J.S. The evaluation of a selection index. Biometrics, North Carolina, v.18, p.375-393, 1962.

ZINSLY, J.R.; MACHADO, J.A. Milho-pipoca. In: PATERNIANI, E.; VIEGAS, G.P. (Eds.). Melhoramento e produção do milho. Campinas: Fundação Cargill, 1987. p.413-421. 